Tropical Journal of Pharmaceutical Research April 2012; 11 (2): 185-192

(C) Pharmacotherapy Group, Faculty of Pharmacy, University of Benin, Benin City, 300001 Nigeria.

All rights reserved.

Available online at http://www.tjpr.org

Research Article

http://dx.doi.org/10.4314/tjpr.v11i2.3

\title{
Formulation of Sustained-Release Matrix Tablets Using Cross-linked Karaya Gum
}

\author{
Mahesh M Reddy, Jagadeeswara D Reddy, Afrasim Moin* and \\ Shivakumar HG \\ JSS College of Pharmacy, JSS University, Mysore, Karnataka-570015, India
}

\begin{abstract}
Purpose: To develop sustained release matrix tablets of diltiazem hydrochloride (DTZ) using modified karaya gum (MK).

Methods: MK was prepared by cross-linking karaya gum with tri-sodium tri-metaphosphate (STMP) which was used as a cross linker. Matrix tablets of DTZ were prepared using varying ratios of unmodified karaya gum $(K)$ and MK by direct compression. The matrix tablets were evaluated for pharmacotechnical properties and in vitro release. The optimized formulation was compared with a reference, Dilzem ${ }^{\circledR}$ SR. MK and the formulations were also characterized by scanning electron microscopy (SEM), Fourier transform infra-red spectroscopy (FTIR) and differential scanning calorimetry (DSC).

Results: Tablets formulated with MK showed higher mean dissolution time (MDT) and lower dissolution efficiency than those prepared with karaya gum. Drug release was by water uptake, diffusion and erosion mechanisms. Drug release for tablets prepared with pure $\mathrm{K}$ was $99.9 \%$ at the end of $10 \mathrm{~h}$ while that tablet made with MK was $68.2 \%$ at the end of $12 \mathrm{~h}$. MK sufficiently controlled the drug release unlike $K$ which exhibited rapid drug release efficiency. SEM images of the tablets before and after dissolution showed some morphological changes on the tablet surface while FTIR and DSC thermogram studies confirmed that there was no chemical interaction between the drug and the polymers in MK formulation. Formulation F6 compared well with Dilzem ${ }^{\circledR} S R$ (reference) $(p<0.05)$ in terms of release characteristics.

Conclusion: The results of the study demonstrate that modified karaya gum is a potential matrix material for formulating suitable sustained-release matrix tablets of diltiazem.
\end{abstract}

Keywords: Karaya gum, Diltiazem hydrochloride, Tri-Sodium tri-metaphosphate, Matrix tablets Sustained release. 


\section{INTRODUCTION}

Of the approaches used for controlling drug release from solid dosage forms, compressed matrices continue to attract considerable attention, as such devices low-cost and high levels of drug can be incorporated in them. Hydrophilic polymers are widely used in the formulation of modified release dosage forms because they are low-cost, and usually show reduced risk of systemic toxicity and minimal incidence of dose dumping. Matrix systems can be used to control the release of both water soluble and water insoluble drugs. Although, their drug release behavior appears simple, but in reality, the release pattern is a complex phenomenon. At the molecular level, it involves water penetration, polymer water uptake, as well as drug dissolution and diffusion as well as polymer water uptake and erosion $[1,2]$.

In recent years, researchers have become increasingly interested in the utilization of biopolymers due to their wide ranging advantages over synthetic polymers. Polysaccharide gums are the materials of choice because they are naturally abundant, biocompatible, biodegradable, and nonimmunogenic $[3,4]$.

Gum karaya, sometimes called as sterculia gum is a complex water-soluble polysaccharide. It is a hydrophilic colloid prepared from the exudates of Sterculia urens tree. It is a partially acetylated complex polysaccharide composed of galacturonic acid, beta-D-galactose, glucuronic acid, Lrhamnose, and other residues obtained as the calcium and magnesium salt [5]. As a bulk laxative, gum karaya is second only to psyllium seeds in importance [6]. When used in bulk laxatives, the gum is usually processed to $500 \mu$ mean particle size. These coarse gum particles absorb water and swell 60 to 100 times their original volume, forming a discontinuous type of mucilage. This type of mucilage is very effective as a laxative. The gum has been evaluated as a controlled release-matrix and has also shown superior mucoadheshion to guar gum [7]. Modification of karaya gum to develop matrix tablets has been reported on extensively in the literature; except for a few works using them as retarding polymers, not much has been done [8].

Tri-sodium tri-metaphosphate (STMP) is a non-toxic cyclic triphosphate, already reported as an effective cross-linker of starches [9], guar gum [10] and hyaluronic acid [11] in order to synthesize gels for pharmaceutical purposes.

Diltiazem hydrochloride (DTZ) is a calcium channel blocker that is widely prescribed for the treatment of hypertension and angina. It is highly water soluble and almost completely absorbed. However, its bioavailability is only 30 to $40 \%$ owing to first pass metabolism, and has an elimination half-life of $3.5 \mathrm{~h}$. Therefore, DTZ requires multiple daily dosing to maintain adequate plasma concentrations. The drug is thus a suitable model candidate for sustained drug delivery [12].

The objective of the present study was to modify karaya gum using STMP as cross linking agent and also to evaluate the modified karaya gum as a suitable, release retardant polymer for the formulation of sustained release tablets of DTZ.

\section{EXPERIMENTAL}

\section{Materials}

Diltiazem hydrochloride (DTZ) and microcrystalline cellulose (MCC) were obtained free of charge from Micro Lab Ltd, Bangalore, India. Karaya gum (K) and trisodium tri-metaphosphate (STMP) were purchased from Sigma Aldrich, Steinheim, Germany, while magnesium stearate, hydrochloric acid, sodium hydroxide, and potassium dihydrogen phosphate were all obtained from Merck, Mumbai, India. All chemicals and reagents used were either of 
pharmaceutical or analytical grades. The reference diltiazem hydrochloride tablet formulation used for the study was Dilzem SR (Torrent Pharma Ltd, India).

\section{Synthesis of modified karaya gum(MK)}

Karaya gum was cross-linked with tri-sodium tri-metaphosphate (STMP) as follows: STMP (1 g) was dissolved in $50 \mathrm{ml}$ of water and added to $5 \mathrm{ml}$ of $0.1 \mathrm{M} \mathrm{NaOH}$ in a $200 \mathrm{ml}$ beaker with $1 \mathrm{~g}$ of karaya gum in $50 \mathrm{ml}$ of water then added slowly with stirring. The reaction mixture containing $100 \mathrm{ml}$ was stirred for a $2 \mathrm{~h}$, poured into five Petri dish, each containing $20 \mathrm{ml}$, and dried at $60{ }^{\circ} \mathrm{C}$ for $24 \mathrm{~h}$. The dried complex (modified gum) was powdered, passed through a $200 \mu$ aperture sieve and used for the formulation of tablets.

\section{Preparation of matrix tablets}

Matrix tablets of $90 \mathrm{mg}$ diltiazem hydrochloride were prepared (based on the composition in Table 1) by direct compression method. The excipients (except magnesium stearate) and drug were first passed through a $200 \mu$ aperture sieve and then mixed in geometrical fashion for $10 \mathrm{~min}$. Finally, the magnesium stearate was added and mixed for additional $2 \mathrm{~min}$. The batch size of each formulation was 50 tablets. The tablets were compressed in a tablet machine (Rimek Mini Press I, Mumbai, India) using 12 $\mathrm{mm}$ flat-faced punches [13].

\section{Physicochemical characterization of tablets}

The hardness and friability of the tablets of tablets were measured with a digital hardness tester (Erweka, Mumbai, India) and friabilator (Electrolab, Mumbai, India), respectively. Content uniformity of DTZ of all batches (10 tablets) was analyzed spectrophotometrically (model UVPC 1601, Shimadzu, Kyoto, Japan) at $237 \mathrm{~nm}$.

Weight variation and uniformity of drug content were assessed for 20 tablets according to Indian Pharmacopoeia (IP) procedures [14]. Twenty tablets were weighed individually and the mean weight determined. The tablets were then powdered, and $100 \mathrm{mg}$ equivalent of the tablet triturate taken in a $100 \mathrm{ml}$ volumetric flask. The volume was made up to mark with simulated gastric fluid ( $\mathrm{pH} 1.2)$ to give Stock I solution. Stock I solution $(10 \mathrm{ml})$ was transferred to $100 \mathrm{ml}$ volumetric flask and diluted up to the mark with buffer (Stock solution II), $3 \mathrm{ml}$ of which was diluted to $25 \mathrm{ml}$ and the solution was filtered through $0.45 \mu \mathrm{m}$ pore membrane. Its absorbance was measured spectrophotometrically (model UVPC 1601, Shimadzu, Kyoto, Japan) at 237 $\mathrm{nm}$.

\section{Scanning electron microscopy (SEM)}

The surface morphology of the matrix tablets was analyzed with a scanning electron microscope (model JSM-840A, Jeol,Japan) before hydration and $6 \mathrm{~h}$ after.

\section{Water uptake and erosion studies}

Water uptake and mass loss were computed gravimetrically according to Eqs 1 and 2 . Three tablets were used per time point. At the predetermined times, the tablets were lightly patted with tissue paper to remove excess surface water. The swollen weight of tablets was determined(Ts) and then the same tablets were dried in a vacuum oven at $40^{\circ} \mathrm{C}$ for $48 \mathrm{~h}$, the remaining dry weight of the tablet (Tf) was determined. The study was carried out in triplicate. Water uptake (\%) and erosion (\%) was calculated using Eqs 1 and 2 , respectively [15].

Water uptake $(\%)=(T s-T) / T \times 100 \ldots . .(1)$ where Ts is the weight of the swollen tablet and $T$ is the initial of the tablet, i.e., prior to the test.

Erosion (\%) $=(T-T f) / T f \times 100$ 
where $T$ is the initial weight of the tablet and $\mathrm{Tf}$ is the weight of the tablet after the erosion test.

\section{FT-IR spectroscopy}

FT-IR studies were carried out using Shimadzu FTIR 8400S. The pellets were prepared with $\mathrm{KBr}$ using pure drug, polymers and crushed tablet formulations. Spectra were recorded in the range of $400-4000 \mathrm{~cm}^{-1}$.

\section{Thermal analysis}

Thermal analysis of samples were carried out with a DSC; Perkin-Elmer, Pyris-1. The analysis was performed on 2 - $4 \mathrm{mg}$ of the drug alone, the polymer and a mixture of the drug and polymer in the range of $0-400{ }^{\circ} \mathrm{C}$. The samples were placed in $\mathrm{zn}$ aluminium pan with a perforated, under nitrogen atmosphere and heating rate of $10^{\circ} \mathrm{C} / \mathrm{min}$.

\section{In vitro release studies}

Dissolution test was carried out using a USP type I apparatus (model TDT-08I, Electrolab, Mumbai, India) at $100 \mathrm{rpm}$ and $37^{\circ} \mathrm{C}$ for the first $2 \mathrm{~h}$ in $900 \mathrm{~mL}$ of simulated gastric fluid $(0.1 \mathrm{M} \mathrm{HCl})$ and immediately continued in 900 $\mathrm{mL}$ of phosphate buffer ( $\mathrm{pH} 7.4$ ). Five $\mathrm{ml}$ of the dissolution fluid was withdrawn at regular time intervals during the studies and replaced with an equal volume of drug-free dissolution fluid to maintain sink conditions. The samples were suitably diluted with fresh dissolution fluid and analyzed for drug release spectrophotometrically at $237 \mathrm{~nm}$.

\section{Kinetic analysis of dissolution data}

To study the mechanism of drug release from the matrix tablets, the release data were fitted to zero-order, first-order, and Higuchi models. The data were also subjected to the Korsmeyer-Peppas exponential equation (Eq 3) which is often used to describe drug release behavior from polymeric systems.

$$
\log \left(M_{t} / M_{f}\right)=\log k+n \log t \ldots \ldots .
$$

Where $M_{t} / M_{f}$ is the fractional release of drug, $\mathrm{k}$ is constant, $\mathrm{ni} \mathrm{s}$ the diffusional exponent, and $t$ is time.

The diffusional exponent, ' $n$ ', which is indicative of the mechanism of drug release, was obtained by plotting the log value of percent drug released against log time for each batch (Eq 3). A value of $n=0.45$ indicates Fickian (case I) release; > 0.45 but $<0.89$ is non-Fickian (anomalous) release; and > 0.89 indicates super case II type of release. Case II generally refers to the erosion of the polymeric chain while anomalous transport (non-Fickian) refers to a combination of both diffusion and erosion controlled-drug release. Dissolution efficiency (DE), defined as the area under the dissolution curve up to a certain time $t$, and expressed as a percentage of the area of the rectangle described by $100 \%$ dissolution in the same time, and mean dissolution time (MDT), were used to translate the profile differences into a single value as shown in Eqs 4 and 5 [16,17].

$$
D E_{12 \%}=\frac{\int_{0}^{t} y d t}{y 100} t \times 100
$$

MDT is a measure of the dissolution rate: the higher the MDT, the slower the release rate.

$$
M D T=\frac{\sum_{i=l}^{i=n} t_{m i d} \times \Delta M}{\sum_{i=l}^{i=n} \Delta M}
$$

where $i$ is the dissolution sample number, $\mathrm{n}$ is the number of dissolution sample time, $t_{\text {mid }}$ is the time at the midpoint between $i$ and $i-1$, and $\Delta \mathrm{M}$ is the amount of drug dissolved between i and i-l. The similarities between two dissolution profiles were assessed by a pair-wise model-independent procedure, similarity factor $\left(f_{2}\right)$.

$f_{2}=50 \log \left\{\left[1+\frac{1}{n \sum_{n=1}^{n=i}\left(R_{t}-T_{t}\right)^{2}}\right]^{-0.5} \times 100\right\} \ldots .$.

where $n$ is the number of pull points, $R_{t}$ is the reference profile at time point $t$, and $T_{t}$ is the test profile at the same time point; the value 
of $f_{2}$ should be between 50 and 100. An $f_{2}$ value of 100 suggests that the test and reference profiles are identical and, as the value becomes smaller, the dissimilarity between release profiles increases [18].

\section{Statistical analysis}

Comparison among the developed formulation and the reference formulation (Dilzem- SR) was carried out by Student ttest at $95 \%$ level of confidence using GraphPad.Prism.Ver.5.0.4.

\section{RESULTS}

\section{Characterization of tablets}

The drug content of the formulations was uniform, being more than $97 \%$ and with less than $1.0 \%$ relative standard deviation. Hardness ranged from $4-6 \mathrm{~kg} / \mathrm{cm}^{2}$ while friability was $<1 \%$. Thus, all the tablet formulations showed acceptable physical characteristics.

\section{In vitro drug release and kinetics}

The in-vitro release results are shown in Figure 1. Drug release of diltiazem hydrochloride from all the formulations in the first hour ranged from 16.8 to $86.6 \%$ while after $12 \mathrm{~h}$, it was between 68.2 and $100.0 \%$. Increase in the content of polymer decreased drug release at the 12th hour.. Burst effect was observed at the $1^{\text {st }}$ hour only in formulations containing low polymer concentration. Formulations containing unmodified karaya gum showed complete drug release in $<12 \mathrm{~h}$ whereas those formulated with modified karaya gum exhibited extended drug release over the 12 $\mathrm{h}$ period. Both the test formulation and the reference showed similar release rates releasing $85 \%$ of their drug content in $12 \mathrm{~h}$.

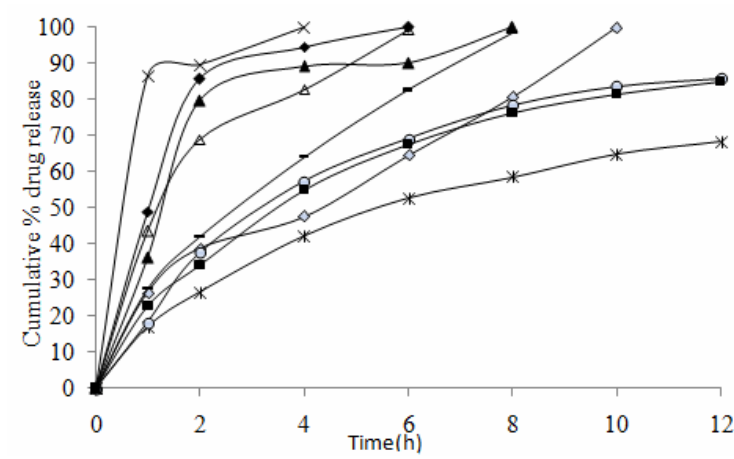

Figure 1: Dissolution profile of formulations (Key: $\diamond=\mathrm{F} 1 ;-=\mathrm{F} 2 ; \Delta=\mathrm{F} 3 ; \mathrm{X}=\mathrm{F} 4 ; *=\mathrm{F} 5 ; \mathrm{O}=\mathrm{F} 6$; $\Delta=\mathrm{F} 7 ; \bullet=\mathrm{F} 8 ; \mathbf{\square}=$ reference standard)

The dissolution kinetic data, mean dissolution time (MDT) and dissolution efficiency $\left(\mathrm{DE}_{12}\right)$ of the formulation are shown in Table 1. MDT ranged from $0.55-3.36 \mathrm{~h}$ while $\mathrm{DE}_{12}$ (at the end of $12 \mathrm{~h}$ ) was $46.0-86.5 \%$. The drug release data of the tableted formulations did not fit satisfactorily to zero-order, first-order but showed good fit into the Korsmeyer equation $\left(r^{2}=0.8346\right.$ to 0.9924$)$ and Higuchi equation $\left(r^{2}=0.860\right.$ to 0.9916$)$, respectively. The value of the release exponent, "n", for the various matrices ranged from 0.0258 to 0.4935. F6 had MDT and dissolution efficiency $\left(D_{12} \%\right)$ similar to those of the standard product, Dilzem SR. The similarity factor $\left(f_{2}\right)$ was 68.75 , suggesting that their dissolution profiles were very similar. Of all the formulations, only F6 did not significantly differ in terms of drug release $(p<0.05)$ from the commercial DTZ product used as standard.

Table 1: Composition, kinetic and dissolution parameters of DTZ (90 mg) matrix tablets

\begin{tabular}{|c|c|c|c|c|c|c|c|c|}
\hline $\begin{array}{l}\text { Formulation } \\
\text { code }\end{array}$ & K & MK & MCC & $\mathbf{n}$ & $K P^{a}$ & Higuchi & $\begin{array}{l}\text { MDT(h) } \pm \\
\text { SD }\end{array}$ & $\begin{aligned} & \mathrm{DE}_{12} \\
\pm & \mathrm{SD}(\%)\end{aligned}$ \\
\hline F1 & 100 & - & 5 & 0.4429 & 0.9924 & 0.9880 & $3.26 \pm 0.2$ & $60.92 \pm 2.3$ \\
\hline F2 & 75 & - & 30 & 0.4935 & 0.9896 & 0.9916 & $3.36 \pm 0.1$ & $70.48 \pm 4.3$ \\
\hline F3 & 50 & - & 55 & 0.4859 & 0.9539 & 0.9846 & $1.87 \pm 0.2$ & $73.32 \pm 5.8$ \\
\hline F4 & 25 & - & 80 & 0.0258 & 0.9442 & 0.8601 & $0.55 \pm 0.3$ & $86.51 \pm 8.9$ \\
\hline F5 & - & 100 & 5 & 0.4884 & 0.9866 & 0.9855 & $3.22 \pm 0.2$ & $46.10 \pm 6.3$ \\
\hline F6 & - & 75 & 30 & 0.3956 & 0.9709 & 0.9481 & $2.50 \pm 0.1$ & $64.00 \pm 4.3$ \\
\hline F7 & - & 50 & 55 & 0.4357 & 0.8974 & 0.9507 & $1.98 \pm 0 \pi^{3}$ & $80.69 \div 26$ \\
\hline F8 & - & 25 & 80 & 0.3307 & 6.8848 & 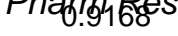 & A.p. $64 \pm 0.2$ & 2, 181 1 $344+7.29$ \\
\hline Standard & DilzemSR & & & 0.5531 & 0.9918 & 0.9862 & $3.54 \pm 0.1$ & $59.82 \pm 3.1$ \\
\hline
\end{tabular}




\section{Scanning electron microscopy (SEM)}

Figure 2 displays the scanning electron micrographs (SEM) of the surface of tablet formulation F6. The micrographs indicate that the surface of the matrix tablet became highly porous after the dissolution.

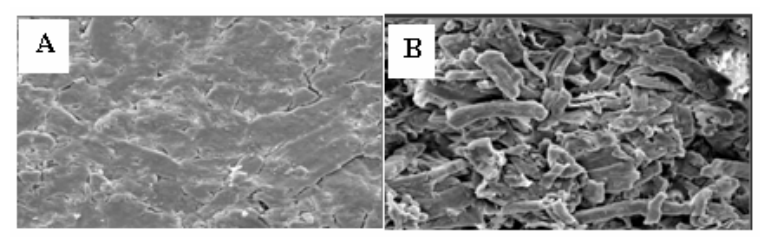

Figure 2: Scanning electron micrographs of tablet formulation $\mathrm{F} 6$ before $(\mathrm{A})$ and $6 \mathrm{~h}$ after (B) dissolution

\section{Water uptake and erosion}

Figure 3 shows the water uptake and erosion profiles for the optimized formulation F6 contained modified karaya gum and the reference (standard) tablets. At the end of 12 $\mathrm{h}$ water uptake for the test formulation and reference standard was 165.5 and $250 \%$, respectively, while erosion was 36.75 and $33.4 \%$, respectively.

\section{FT-IR spectroscopy}

As observed from the Figure 4, the pure karaya gum peaks are associated to the hydrogen bonded $\mathrm{OH}$ groups, two peaks are indicative of acetyl groups and the other two peaks are attributed to COO- groups of uronic acid residues. In modified karaya gum, the stunted broadened peak which appeared at $3428 \mathrm{~cm}^{-1}$ is attributed to the overlap of N$\mathrm{H}$ stretching band of amide group and $\mathrm{O}-\mathrm{H}$ stretching band. Disappearance of acetyl groups in modified gum is also observed. The appearance of new peaks which were absent in karaya gum are attributed to phosphate-I ($\mathrm{C}=\mathrm{O}$ stretching) and phosphate-II (-C-O bending) of the phosphate group of STMP thus confirming the cross-linking reaction. The FTIR spectra of pure drug and formulation F6 showed characteristic peaks for both pure DTZ and DTZ in the test matrix formulation without any significant shift in their positions.
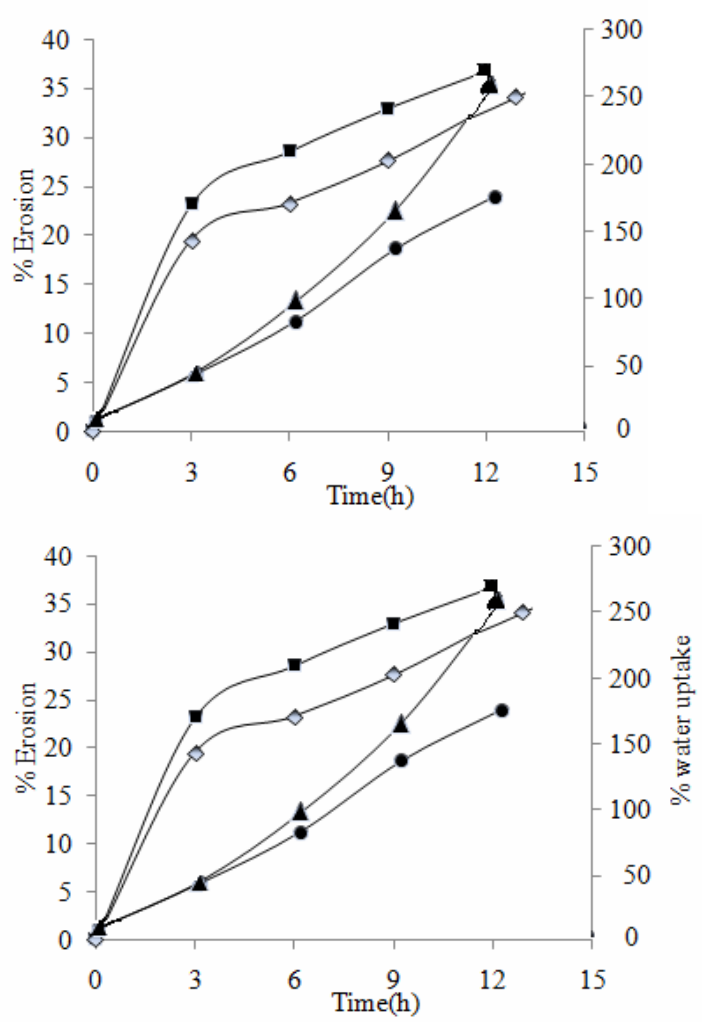

Figure 3: Water uptake and eroding behaviour of test formulation F6 $(-\mathbf{v})$ and standard formulation $(\boldsymbol{\Delta}, \diamond)$.

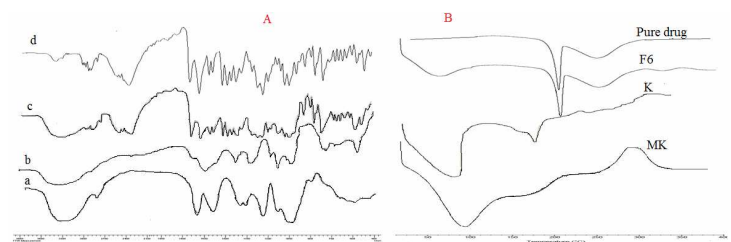

Figure 4: $A=$ FT-IR spectra of a) unmodified karaya gum, b) modified karaya gum, c) F6 and d) pure drug; $B=D S C$ thermograms of unmodified karaya gum, modified karaya gum, F6 and pure drug

\section{Thermal analysis}

As Fig 4B indicates, the DSC thermograms of unmodofied karaya gum (K) showed endothermic peaks at 85.3 and $186.7^{\circ} \mathrm{C}$, but 
modified karaya gum (MK) showed an endothermic peak at $85.3{ }^{\circ} \mathrm{C}$ and a new exothermic peak at $259.4{ }^{\circ} \mathrm{C}$. The DSC thermograms of formulation F6 and pure DTZ showed endothermic peaks for the pure drug and the drug in the formulation at 216.4 and $218.6^{\circ} \mathrm{C}$, respectively.

\section{DISCUSSION}

\section{Drug release}

The rate of drug release tended to decrease with increase in the amount of polymer. This is in agreement with previous works which suggested that the viscosity of the gel layer around the drug particles in the tablet increases with increase in hydrogel concentration thus limiting the release of the drug [19]. The gel formed during the penetration of dissolution media into the matrix structure, consists of closely packed swollen particles. With further increase in polymer content, thicker gel forms, inhibiting the dissolution fluid penetration and resulting in significant reduction in drug release (compare $\mathrm{F} 5$ and $\mathrm{F} 6$ with other test formulations). Formulations with low polymer concentrations as well as unmodified karaya gum rapidly hydrated and formed weak matrix systems which accounted for the 'burst' release as well as rapid release.

Furthermore, crosslinking in the modified karaya gum resulted in matrix rigidity, thereby slowing the hydration rate of the gum; this, in conjuction with erosion, resulted in controlled release of drug which was incomplete at the of $12 \mathrm{~h}$. Among the test formulations, F6 was most similar to the standard product, Dilzem $\mathrm{SR}$, with a similarity factor of 68.75 . The release data showed close affinity to the Korsmeyer-Peppas model. The release exponent " $n$ " value was characteristic of Fickian diffusion and indicated a combined effect of diffusion and erosion mechanisms for controlled drug release.

The SEM photomicrograph of the tablets after $6 \mathrm{~h}$ after hydration commenced showed a highly porous tablet surface which suggest a porous tablet matrix structure. This confirms that drug release was by diffusion from the tablet core to the surface. Since the gel layer undergoes surface erosion, it is possible that the inner porous network is exposed after the erosion-dissolution of the outer layer of the matrix. The presence of both pores and gel structure on the tablet surface indicates involvement of both erosion and diffusion mechanisms for sustained drug release.

Thus the matrices underwent both water uptake and erosion simultaneously immediately after placement in the dissolution medium and this continued over the $12 \mathrm{~h}$ period of the study. Formulation F6 and the standard DTZ product had overlapping erosion profile but their water uptake behaviour was similar only up to the 6th hour. The plots were almost linear, indicating a balance between water uptake and erosion, and resulting in sustained drug release [20].

The DSC thermogram of MK, when compared to pure karaya, showed a main broad endothermic peak. But the other peak which appeared at $186.7^{\circ} \mathrm{C}$ disappeared withthe appearance of a new exothermic peak. Thus the above data obtained indicates a change in the structure of karaya gum. Also, the DSC endothermic peaks for the pure drug and the drug in the formulation F6 showed only a negligible shift in their positions with some peak broadening in the latter. Thus it seems from both FT-IR and DSC results that karaya gum structure was modified by crosslinking, and that the likelihood of any chemical interaction between the drug and the polymers does not exist.

\section{CONCLUSION}

This study demonstrates the crosslinking of karaya gum enhances matrix rigidity, thereby sustaining drug release rate when compared to natural gum. Although karaya gum structure was modified by crosslinking, there was no any chemical interaction between the drug and the polymers used. Overall, the results of the study indicate that modified 
karaya gum would be suitable for formulating sustained-release matrix tablets of diltiazem.

\section{ACKNOWLEDGEMENT}

The authors acknowledge J.S.S. Mahavidyapeetha, Mysore and JSS University, Mysore, India, for their invaluable support during this work. The authors wish to thank to IISC, Bangalore, India for providing facilities for SEM and DSC studies.

\section{REFERENCES}

1. Viriden $A$, Wittgren $B$, Larsson $A$. Investigation of critical polymer properties for polymer release and water uptake of HPMC matrix tablets. Eur J Pharm Sci 2009; 36: 297-309.

2. Hiremath PS, Saha RN. Controlled Release Hydrophilic Matrix Tablet Formulations of Isoniazid: Design and In Vitro Studies. AAPS PharmSciTech 2008; 9(4): 1171-1178.

3. Bhardwaj TR, Kanwar M, Lal R, Gupta A. Natural gums and modified natural gums as sustainedrelease carriers. Drug Dev Ind Pharm 2000; 26(10): 1025-1038.

4. Coviello T, Matricardi P, Marianecci C, Alhaique F. Polysaccharide hydrogels for modified release formulations. J Control Release 2007; 119: 524.

5. Weiping W. Tragacanth and karaya, in: Philips GO, Williams PA (Eds.). Handbook of Hydrocolloids. Woodhead, Cambridge; 2000; $p$ 155.

6. Meier P, Seiler WO, Stahelin HB. Bulk-forming agents as laxatives in geriatric patients. Schweiz Med. Wochenschr. 1990; 120(9): 314-321.

7. Park CR, Munday DL. Evaluation of selected polysaccharide excipients in buccoadhesive tablets for sustained release of nicotine. Drug Dev. Ind. Pharm. 2004; 30(6): 609.

8. Verbeken D, Dierckx S, Dewettinck K. Exudate gums: occurrence, production, and applications. Appl Microbiol Biotechnol 2003; 63(1): 10-21.

9. Wurzburg $O B$, in: Wurzburg $O B$ (Eds.). Modified Starches: Properties and Uses. CRC Press Boca Raton, Florida; 1986; pp 42-52.
10. Gliko-Kabir I, Yagen B, Penhasi A, Rubinstein A. Phosphated crosslinked guar for colon-specific drug delivery: I. Preparation and physicochemical character. J Control Release 2000; 63: 121-129.

11. Dulong V, Lack S, Le Cerf D, Picton L, Vannier JP, Muller G. Hyaluronan-based hydrogels particles prepared by crosslinking with trisodium trimetaphosphate. Synthesis and characterization. Carbohydr Polym, 2004; 57: 1-8.

12. Gambhire $M N$, Ambade $K W$, Kurmi $S D$, Kadam VJ, Jadhav KR. Development and in vitro evaluation of an oral floating matrix tablet formulation of diltiazem hydrochloride. AAPS PharmSciTech 2007; 8(3): E1-E9.

13. Afrasim Moin, HG Shivakumar. Formulation of Sustained-Release Diltiazem Matrix tablets Using Hydrophilic Gum Blends. Trop J Pharm Res, 2010; 9 (3): 283-291.

14. Government of India Ministry of Health and Family Welfare; The Pharmacopoeia of India 1996, Volume II; New Delhi; Controller of Publication; p. $734-736$.

15. Varshosaz J, Tavakoli N, Kheirolahi F. Use of hydrophilic natural gums in formulation of sustained-release matrix tablets of tramadol hydrochloride. AAPS PharmSciTech 2006; 7(1): E1-E7.

16. Durig $T$, Fassihi $R$. Guar-based monolithic matrix systems: effect of ionizable and non-ionizable substances and excipients on gel dynamics and release kinetics. J Control Release 2002; 80: 45-56.

17. Kuksal A, Tiwary AK, Jain NK, Jain S. Formulation and in vitro, in vivo evaluation of extendedrelease matrix tablet of zidovudine: influence of combination of hydrophilic and hydrophobic matrix formers. AAPS PharmSciTech 2006; 7(1): E1-E9.

18. Costa P, Sousa Lobo JM, Gohel MC, Panchal MK. Modeling and comparison of dissolution profiles. Eur J Pharm Sci 2001; 13(2): 123133.

19. Chandran S, Ravi R, Saha RN. Development and In vitro Evaluation of Oral Controlled Release Formulations of Celecoxib Using Optimization Techniques. Yakugaku zasshi 2006; 126(7): 505-515.

20. Sujja-areevath J, Munday DL, Cox PJ, Khan KA. Relationship between water uptake, erosion and drug release in hydrophillic natural gum mini-matrix formulations. Eur J Pharm Sci 1998; 6: 207-217.

Trop J Pharm Res, April 2012;11 (2):192 